Review

\title{
Parathyroid Carcinoma: A Review with Three Illustrative Cases
}

\section{Antoine Digonnet ${ }^{1}$, Adelaïde Carlier ${ }^{1}$, Esther Willemse ${ }^{1}$, Marie Quiriny ${ }^{1}$, Cécile Dekeyser ${ }^{1}$, Nicolas de Saint Aubain $^{3}$, Marc Lemort ${ }^{2}$, Guy Andry ${ }^{1 凶}$}

1. Department of Head and Neck Surgery, Free University of Brussels. Jules Bordet institute, 1000 Brussels, Belgium.

2. Department of Radiology, Free University of Brussels. Jules Bordet institute, 1000 Brussels, Belgium.

3. Department of Pathology, Free University of Brussels. Jules Bordet institute, 1000 Brussels, Belgium.

Corresponding author: Antoine Digonnet, Jules Bordet institute, rue Heger Bordet, 1, 1000, Brussels, Belgium. Tel: +322 5413319 Fax: +3225413141 antoine.digonnet@bordet.be

(c) Ivyspring International Publisher. This is an open-access article distributed under the terms of the Creative Commons License (http://creativecommons.org/ licenses/by-nc-nd/3.0/). Reproduction is permitted for personal, noncommercial use, provided that the article is in whole, unmodified, and properly cited.

Received: 2011.08.21; Accepted: 2011.10.20; Published: 2011.10.27

\begin{abstract}
Parathyroid carcinoma is a rare disease, which accounts for less than $1 \%$ of all case of primary hyperparathyroidism and is usually not detected until the time of surgery or thereafter. For most patients preoperative staging is not available. A radical excision remains the standard management; the place of adjuvant radiotherapy is not well established yet. Local recurrence and/or the metastases are unfortunately frequent. The present paper presents an up to date review of the literature illustrated by three clinical cases.
\end{abstract}

Key words: parathyroid carcinoma, hypercalcemia, hyperparathyroidism, prognosis, surgery, methylene blue, radiotherapy

\section{Introduction}

Parathyroid carcinoma, a rare endocrine malignancy, accounts for less than $1 \%$ of cases of sporadic primary hyperparathyroidism. Clinical manifestations are generally more severe than in common benign diseases such as parathyroid adenoma or hyperplasia.

When diagnosed, this neoplasm is a solitary lesion but anecdotal cases of multiple lesions have been described 1 , extremely rarely were bilateral parathyroid carcinomas reported ${ }^{2}$.

Usually the disease has an indolent but slowly progressive course. Most of the patients will die due to complications of hypercalcemia, rather than direct tumor invasion or metastases. The management of PC is difficult in terms of diagnosis, treatment and follow-up.

The distinction between malignant and benign lesions of the parathyroid is difficult, even with a histopathological examination. For most patients preoperative staging is not available. Intraoperative findings are important: the surgeon has to distinguish between an adenomatous disease and a carcinoma ${ }^{3}$. A radical excision remains the standard management; the place of adjuvant radiotherapy is not well established yet.

Local recurrence and/or metastases are unfortunately frequent.

We present here a review focused on the most recent advances in parathyroid carcinoma illustrated by three patients treated at our institution.

\section{Clinical presentation}

Parathyroid carcinomas, a rare entity, accounts for less than $1 \%{ }^{4,5}$ of all cases of primary hyperparathyroidism. A higher incidence has been reported in Japan and Italy where it rises up to 5-5,2\%. ${ }^{6,7}$

It is habitually a sporadic disease, but familial cases have been described. 
Parathyroid carcinoma occurs equally in men and women, while benign parathyroid disease predominates in women by a ratio of 3-4:1.

The average age of diagnosis is the fourth decade of life whereas for benign adenomas the average age is thirty ${ }^{8}$. The 3 patients treated at our institution were respectively 35, 58, 76 years old, 2 women and 1 man

Paratyhyroid carcinomas have been described in $15 \%$ of hyperparathyroidism-jaw tumor (HPT-JT) syndrome, a rare autosomal disorder. In HPT-JT, ossifying fibromas of the maxilla and mandible are seen in $30 \%$ of cases $^{9}$. Less commonly, kidney lesions including cysts, polycytic disease, harmartomas or Wilm's tumor can be present.

Although parathyroid carcinomas are not a feature of multiple endocrine neoplasia type 1 (MEN 1), recently ${ }^{10-11}$ parathyroid carcinomas have been described in MEN 1. According to our Knowledge, only one case of parathyroid carcinoma has been reported in MEN 2 a syndrome ${ }^{12}$.

More than $90 \%$ of parathyroid carcinomas (PCA) are functional, and as such, the clinical features are due primarily to the effects of markedly elevated serum PTH and calcium levels. The most frequent complaints are weakness, fatigue, anorexia, nausea, vomiting, loss of weight, dyspepsia, constipation, headaches, polydipsia and polyuria. Bone, joint, muscular pain, pathological fractures, and renal stones are frequent when hyperparathyroid state is severe. Recurrent severe pancreatitis, anemia and peptic ulcer disease can also occur. Among our 3 patients, 2 were symptomatic. One patient experienced fatigue, ankle and knee pain and the other fatigue, polyuria and polydipsia.

All those clinical signs are unspecific and often lead to a delayed diagnosis; furthermore even with a hypercalcaemia biologically proven, diagnosis may be missed. This was the case for all our patients before referral; all of them have been treated in the setting of a longstanding disease with a tumor size ranging from $4.5 \mathrm{~cm}$ to $7 \mathrm{~cm}$.

A palpable mass in the neck is found in $30-76 \%$ of patients with parathyroid carcinoma ${ }^{13}$. This clinical finding can help to differentiate between a benign and a malignant parathyroid disease; indeed fewer than $5 \%$ of patients with benign disease have a palpable neck mass ${ }^{14}$. The American national cancer data base 15 confirmed in a report of 286 PCA a median size of $3.3 \mathrm{~cm}$. Despite this size, we would like to underline the fact that, due to intrathoracic localization, a palpable mass was not found in 1 of our patients.

\section{Diagnosis}

Higher serum PTH and calcium levels than in parathyroid benign disease may be useful in the diagnosis of PCA. PTH levels higher than $300 \mathrm{pg} / \mathrm{ml}$ are indicator of potential malignant disease. In our population PTH level ranged from 642 to $1192 \mathrm{pg} / \mathrm{ml}$ (N $15-80 \mathrm{pg} / \mathrm{ml})$. Iacobone et al ${ }^{16}$ reminded that these high values should be considered as risk factors in individual patients. Owen et al ${ }^{17}$ state that the presence of vocal cord palsy should alert the examiner of the possibility of cancer in a patient with hyperparathyroidism. Thus, until proven otherwise, the patient should be considered to have a thyroid or parathyroid cancer.

Ultrasound and tomography allow defining the extent of a neck mass. The ultrasound appearance of PCA is a hypo echoic soft tissue mass with irregular, poorly defined border and sign of invasion of adjacent structures ${ }^{18}$. Ultrasonography (US) revealed neck mass in 2 patients, no signs of invasion was found. One PCA was located under the thyroid capsule and appeared like and enlarged thyroid lobe, the other presented like a cystic mass at the inferior aspect of thyroid lobe. The latter located in the thorax was not detected on ultrasound.

Tomography Density measurements can assist in differentiating abnormal parathyroid tissues from lymph nodes and normal thyroid tissue ${ }^{19}$.

However, the only feature that may permit the preoperative diagnosis of parathyroid cancer is clear evidence of invasion into adjacent tissue. Tomography was performed in one patient and demonstrated a cystic mass at the inferior aspect of the thyroid lobe (Fig 1).

Differential diagnosis includes thyroid carcinoma and benign parathyroid disease 19 .

With a sensitivity of $91 \%$ MIBI scintigraphy may be a valid tool to assess the presence and localization of PCA. However, in a study dealing with 19 PCA ${ }^{16}$, scintigraphy failed to localize mediastinal recurrences and pulmonary metastases.

The patient with negative US underwent MIBI scintigraphy (Fig 3) which allowed us to localize an intra thoracic parathyroid carcinoma.

Given the lack of reliable factors to diagnose PCA, it is preferable to suspect it than fail to diagnose it because inadequate surgery leads to recurrences.

\section{Pathogenesis}

Over the last years the development and pathophysiology of parathyroid carcinoma has become clearer. Oncogenes and tumor suppressor genes haves been linked to parathyroid carcinomas. There is no 
definitive evidence of a primary role but altered expressions of these genes may play a part in the process of malignant transformation. Five genes with a potential role in malignancy have been identified and studied: p53, breast carcinoma susceptibility (BRCA2), cyclin D1/parathyroid adenomatosis gene 1 (PRAD1), retinoblastoma tumor suppressor gene (RB) and hyperparathyroidism 2 tumor suppressor gene (HRPT2) ${ }^{8}$.

The HRPT2 gene has provided the best evidence. This gene is also responsible for the hyperparathyroidism with jaw-tumor syndrome (HPT-JT). PCA occurs with higher frequency in HPT-JT patient than in sporadic PHHT $(15 \%$ versus< $1 \%{ }^{20}$. HRPT2 may also play a role in the pathogenesis of sporadic PCA. Shattuck et $\mathrm{al}^{21}$ found HPRT2 mutation in 10 of 15 patients with sporadic PCA.

The prevalence of HPRT2 mutation in sporadic PCA may be as high as $76.6 \%$. Most mutations are nonsense forms leading to a lack or reduction of the encoded protein expression. HPRT2 encodes a protein called parafibromin (parathyroid disease and fibro-osseous lesions) which is a tumor suppressor protein. Parafibromin is involved in the cell cycle regulation by inhibiting cell proliferation by blocking cyclin D1 expression.

Cyclin D1 is highly expressed in parathyroid carcinomas, in a study by Vassef et al 22 91\% (10/11) of PCA specimens were positive for cyclin D1 over expression compared with $39 \%(11 / 28)$ of the adenoma specimens. Cyclin D1 over expression may be a result of loos of parafibromin expression.

\section{Surgical management}

Even by experienced surgeons, up to $86 \%$ of PCA have been missed initially. The result is enucleation or piece meal resection, with the risk of tumor seeding in the operative field ${ }^{15}$. Surgery is the only effective and curative treatment of PC; it should be performed as "en bloc" tumor resection with ipsilateral thyroidectomy to avoid any capsular rupture. In the present report surgery had been undertaken under IV methylene blue perfusion, thus obtaining a better localization of the PC and allowing us a complete resection. Kuriloff 23 et al demonstrate that methylene blue facilitates the identification of abnormal parathyroid tissue in $97 \%$ and a dark blue purple staining was observed in $89 \%$. Methylene blue helped to localize PC in our patients except the one located beneath the thyroid capsula. This condition allowed us to perform in each case an "en bloc" removal of the tumor.

Intra operative (io) monitoring of intact PTH has proven its utility in predicting cure rate in benign hyperparathyroidy ${ }^{24}$. Few studies address the issues of ioPTH monitoring in PCA. Solorzano et al 25 demonstrated, that after an "en bloc" removal of PCA, a drop of $>50 \%$ from baseline was predictive at least 6 months of normocalcemia. Abdelgadir et al ${ }^{26}$ reached the same results and conclude that ioPTH monitoring is accurate in predicting normocalcemia after initial "en bloc" resection.

Furthermore we believe that a significant drop $(>50 \%)$ of ioPTH could be the reflection of an optimal surgery with "en bloc" resection of the lesion. PTH assay was undertaken just after surgery and strongly decreased in all patients ranging from 8 to $70 \mathrm{pg} / \mathrm{ml}$.

The management of recurrent or metastatic PC is primarily surgical ${ }^{13}$. Recurrences in the neck should be treated with wide resection including the regional lymph nodes. Recent data demonstrated that omission of lymph node resection carried a 1.5-2-fold higher risk for recurrence and death at 5 days ${ }^{27}$.

All our patients underwent a central lymph node dissection; none of them had invaded lymph nodes.

Distant metastasis should be excised if possible. Although resection of distant metastases or other foci of malignant tissue is rarely curative; their removal may result in a long period of normocalcemia, ranging from months to years ${ }^{13}$.

\section{Pathology}

The differential diagnosis between parathyroid carcinoma and adenoma is difficult for the pathologist. Grossly, parathyroid carcinomas can be indistinguishable from adenomas. They are usually present as larger masses that are adherent to adjacent structures, but these adherences are not diagnosed as periglandular fibrosis occasionally occurs in adenomas following haemorrhage 28,29 .

Histologically, a definitive diagnosis of malignancy should be restricted to tumors displaying evidence of vascular invasion, capsular invasion with growth into adjacent tissues, or metastases. As criteria for malignancy are mostly architectural and require adequate sampling, frozen sections are of little value. Criteria for vascular and capsular invasion are similar to those used in thyroid pathology: vascular invasion should be observed in the capsule or in the surrounding soft tissues rather than inside the tumor. The presence of thick intratumoral fibrous bands is often regarded as a good indicator of malignancy but it is inconstant and not pathognomonic. Diffuse nuclear enlargement with macronucleoli suggests malignancy. However, these atypia are only observed in $2 / 3$ of carcinomas and focal pleomorphism is common in adenomas 29,17 . 


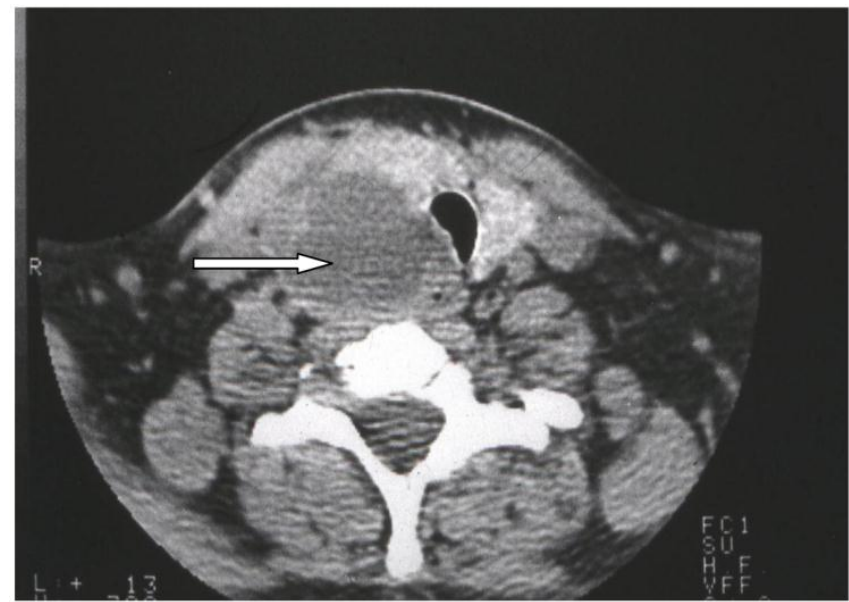

Figure I: Enhanced neck computed tomography showing a cystic mass (arrow) at the inferior aspect of the right thyroid lobe with a tracheal compression.
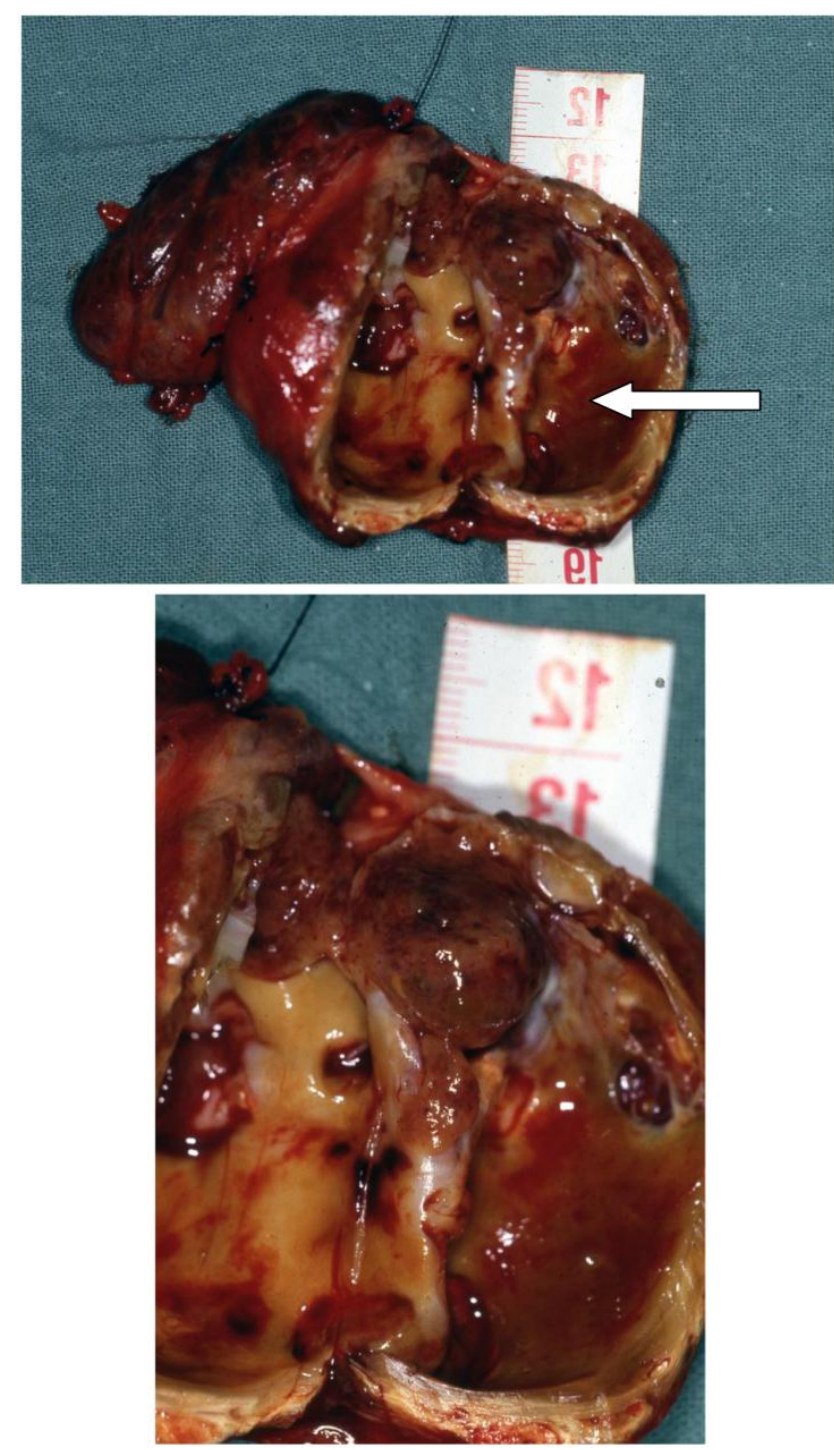

Figure 2: Cystic mass (arrow) $(5,5 \times 3,5 \times 3,5 \mathrm{~cm})$ against the right thyroid lobe

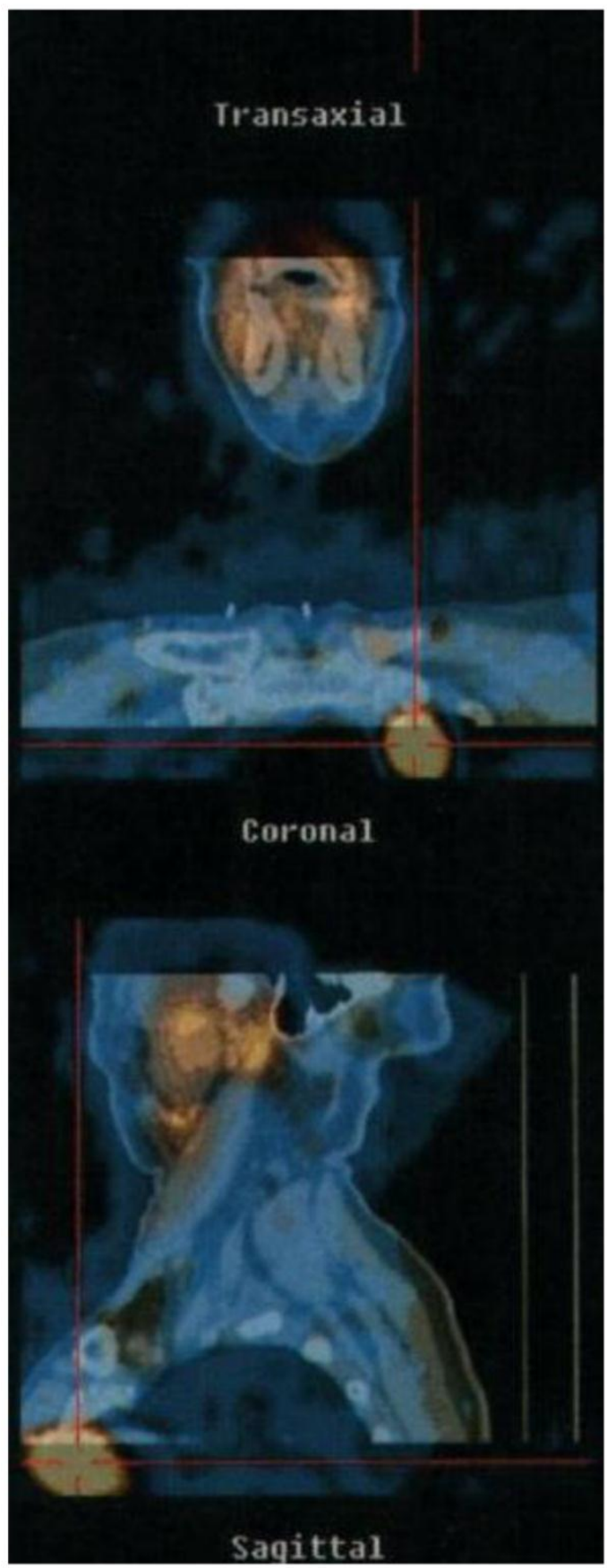

Figure 3: Preoperative MIBI isotopic scan disclosing a left anterior mediastinal captation

\section{Adjuvant therapy}

Two patients underwent radiotherapy (60-65gy) after surgery for capsular and vascular invasion. During irradiation time PTH level decreased from 119 $\mathrm{pg} / \mathrm{ml}$ to $75 \mathrm{pg} / \mathrm{ml}$ and from 71 to $41 \mathrm{pg} / \mathrm{ml}$ suggesting a cytototoxic effect on residual tumor cells. The efficiency of radiation therapy in parathyroid carcinoma remains controversial 30,31, and radiother- 
apy have been reported to be ineffective. The controversy stems from 2 points. Firstly, the first studies performed with subjects with bulky neck disease who had not undergone surgery, have failed to demonstrate either a reduction in the mass of malignant tissue or the attainment of normocalcemia. The common belief is that radiation therapy does not result in a meaningful antitumor response ${ }^{32,33}$. Secondly, all the studies dealing with radiotherapy as adjuvant therapy include a small number of patients without any comparison, thus no strong conclusion can be drawn. The M.D. Anderson group treated 6 of 18 patients suffering from invasive parathyroid cancer with adjuvant radiotherapy in doses of 50 to 63 gy. Five of 6 did not recur locally suggesting that radiation therapy could be effective in prevention of recurrence. A series from the mayo clinic reviewed 61 patients with PCA, 57 underwent en bloc surgery alone and 4 surgery with adjuvant radiotherapy. The 4 patients who received adjuvant radiotherapy were alive with no recurrences at 60 months whereas 25 patients $(44 \%)$ had locoregional recurrence at a median time of 27 months after surgery.

Both data suggest that radiotherapy could be helpful as adjuvant therapy in preventing tumor regrowth after surgery 35,36 . There is no consensus in the literature regarding the doses to be administered but these studies report doses ranging from 50 to $66 \mathrm{~Gy}$. In the present report, no recurrence occurred 2 and 4 years after surgery.

However, Prognosis is not predictable, because when malignancy is confirmed, recurrences occur in most case. The average time of recurrence is approximately 3 years, although longer intervals up to 20 years have been reported ${ }^{14}$.

\section{Conclusion}

PC is a very rare disease and probably an under-diagnosed pathology. This condition leads to a delayed diagnosis when the tumor is already palpable.

Patients with persistent unexplained hypercalcemia should undergo a complete focusing including neck imaging (US/CT/MRI) and MIBI isotopic scan. In the setting of a suspected PC, neck exploration must be performed with an "en bloc" resection of the lesion with ipsi lateral thyroid lobectomy to avoid capsular rupture. A systematic central lymph node resection may improve outcomes in PC.

Adjuvant radiotherapy appears to limit tumor regrowth after surgery.

Since recurrences up to 20 years have been described, patients should undergo a life time follow up.

\section{Conflict of Interest}

The authors have declared that no conflict of interest exists.

\section{References}

1. Chiofalo MG, Scognamiglio F, Losito $S$, et al. Huge parathyroid carcinoma: clinical considerations and literature review. World Journal of surgical oncology 2005; 3:39.

2. Yuan S-F, Yan W, Ji G, Lv Y-G, Wang L. Surgical therapy of bilateral parathyroid carcinoma: Report of an unusual case. EJSO 2010; 36: 107-109.

3. Ter Haar R W, Shen W T, Valk G D, Borel Rinkes I HM, Vriens M R. Parathyroid Carcinoma, a Rare Entity with Varying Presentation and Treatment. World Journal of Endocrine Surgery 2010; 2(1): 33-36.

4. Obara T, Okamoto T, Kanbe M, Lihara M. Functioning parathyroid carcinoma: clinicopathologic features and rational treatment. Semin Surg Oncol 1997; 13: 134-141.

5. Obara T, Fujimoto $Y$ : Diagnosis and treatment of patients with parathyroid carcinoma. An update and review. World J Surg 1991; 15: 738-744.

6. Lumachi F, Basso S.M.M, Basso U. Parathyroid Cancer: Etiology, Clinical Presentation and Treatment. Anticancer Research 2006; 26: 4803-4808.

7. Favia G, Lumachi F, Polistina F, D'Amico DF. Parathyroid carcinoma: sixteen new cases and suggestions for correct management. World J Surg 1998; 22: 1225-1230

8. Marcocci C, et al. Review: Parathyroid carcinoma. J Bone Mineral Res 2008; 23(12): 1869-1880.

9. Carpten JD, Robbins CM, Villablanca A, et al. HRPT2 encoding parafibromin, is mutated in hyperparathyroidism-jaw tumor syndrome. Nat Genet. 2002 Dec;32(4):676-80..

10. Dionisi S, Minisola S, Pepe J, et al. Concurrent parathyroid adenomas and carcinoma in the setting of multiple endocrine neoplasia type 1: presentation as hypercalcemic crisis. Mayo Clin Proc. 2002 Aug;77(8):866-9

11. Haven CJ, van Puijenbroek $M$, Tan MH, et al. Identification of MEN1 and HRPT2 somatic mutations in paraffin-embedded (sporadic) parathyroid carcinomas. Clin Endocrinol (Oxf). 2007 Sep;67(3):370-6.

12. Jenkins PJ, Satta MA, Simmgen M, et al. Metastatic parathyroid carcinoma in the MEN2A syndrome. Clin Endocrinol (Oxf). 1997 Dec;47(6):747-51.

13. Shane E. Clinical review 122: Parathyroid carcinoma. J Clin Endocrinol Metab 2001; 86: 485-493

14. Mittendorf EA, McHenry CR: Parathyroid carcinoma. Journal of Surgical Oncology 2005; 89: 136-142.

15. Hundahl SA, Fleming ID, Fremgen AM, et al. Two hundred eighty-six cases of parathyroid carcinoma treated in the U.S. between 1985-1995: a National Cancer Data Base Report. The American College of Surgeons Commission on Cancer and the American Cancer Society. Cancer. 1999 Aug 1;86(3):378-80.

16. Iacobone M, Lumachi F, Favia G. Up-to-date on parathyroid carcinoma: analysis of an experience of 19 cases. J Surg Oncol. 2004 Dec 15;88(4):223-8.

17. Owen RP, Silver CE, Pellitteri PK, Shaha AR et al. Parathyroid carcinoma: A review. Head Neck 2011; 33: 429-436.

18. Daly BD, Coffey SL, Behan M. Ultrasonographic appearances of parathyroid carcinoma. Br J Radiol. 1989 Nov;62(743):1017-9.

19. Ernst O. Hyperparathyroidism: CT and MR findings. J Radiol. 2009 Mar;90(3 Pt 2):409-12.

20. Howell VM, Haven CJ, Kahnoski K, et al. HRPT2 mutations are associated with malignancy in sporadic parathyroid tumours. J Med Genet. 2003 Sep;40(9):657-63. 
21. Shattuck TM, Välimäki S, Obara T, et al. Somatic and germ-line mutations of the HRPT2 gene in sporadic parathyroid carcinoma. N Engl J Med. 2003 Oct 30;349(18):1722-9.

22. Vasef MA, Brynes RK, Sturm M, et al. Expression of cyclin D1 in parathyroid carcinomas, adenomas, and hyperplasias: a paraffin immunohistochemical study. Mod Pathol. 1999 Apr;12(4):412-6

23. Kuriloff DB, Sanborn KV. Rapid intraoperative localization of parathyroid glands utilizing methylene blue infusion. Otolaryngol Head Neck Surg. 2004 Nov;131(5):616-22.

24. Irvin GL 3rd, Solorzano CC, Carneiro DM. Quick intraoperative parathyroid hormone assay: surgical adjunct to allow limited parathyroidectomy, improve success rate, and predict outcome. World J Surg. 2004 Dec;28(12):1287-92.

25. Solórzano CC, Carneiro-Pla DM, Lew JI, et al. Intra-operative parathyroid hormone monitoring in patients with parathyroid cancer. Ann Surg Oncol. 2007 Nov;14(11):3216-22.

26. Abdelgadir Adam M, Untch BR, Olson JAJr. Parathyroid carcinoma: current understanding and new insights into gene expression and intraoperative parathyroid hormone kinetics. Oncologist. 2010;15(1):61-72.

27. Schulte KM, Talat N, Miell J, Moniz C, Sinha P, Diaz-Cano S. Lymph node involvement and surgical approach in parathyroid cancer. World J Surg. 2010 Nov;34(11):2611-20.

28. Levin KE, Galante M, Clark OH. Parathyroid carcinoma versus parathyroid adenoma In patients with profound hypercalcemia. Surgery. 1987 Jun;101(6):649-60
29. Bondeson L, Grimelius L, deLellis RA, et al. Parathyroid carcinoma. In: DeLellis RA, Lloyd RV, Heitz PU, Eng C, Eds. Tumours of endocrine organs. Lyon: IARCPress. 2004: 128-32.

30. Wynne AG, van Heerden J, Carney JA, Fitzpatrick LA. Parathyroid carcinoma: clinical and pathologic features in 43 patients. Medicine (Baltimore). 1992 Jul;71(4):197-205.

31. Sandelin K, Auer G, Bondeson L, Grimelius L, Farnebo LO. Prognostic factors in parathyroid cancer: a review of 95 cases. World J Surg. 1992;16(4):724-31

32. Chow E, Tsang RW, Brierley JD, et al. Parathyroid carcinoma--the Princess Margaret Hospital experience. Int J Radiat Oncol Biol Phys. 1998 Jun 1;41(3):569-72.

33. Fujimoto $Y$, Obara T, Ito $Y$, et al. Surgical treatment of ten cases of parathyroid carcinoma: importance of an initial en bloc tumor resection. World J Surg. 1984 Jun;8(3):392-400

34. Holmes EC, Morton DL, Ketcham AS. Parathyroid carcinoma: a collective review. Ann Surg. 1969 Apr;169(4):631-40.

35. Munson ND, Foote RL, Northcutt RC et al. Parathyroid carcinoma: is there a role for adjuvant radiation therapy? Cancer. 2003 Dec 1;98(11):2378-84.

36. Rasmuson T, Kristoffersson A, Boquist L. Positive effect of radiotherapy and surgery on hormonally active pulmonary metastases of primary parathyroid carcinoma. Eur J Endocrinol. 2000 Dec;143(6):749-54 